\title{
Intensified Induction Chemotherapy in Locally Advanced Squamous Cell Carcinoma of the Anus-A Population-Based Experience from the Danish Anal Cancer Group
}

\author{
Karen Lycke Wind ${ }^{1, *}$, Lisbeth Riber ${ }^{2}$, Birgitte Mayland Havelund ${ }^{2}$, Eva Serup-Hansen ${ }^{3}$, Camilla Kronborg ${ }^{4}$, \\ Mette Marie Fode ${ }^{5}$, Anders Jakobsen ${ }^{2,+}+\mathbb{D}$ and Karen-Lise Garm Spindler ${ }^{1,+}$ \\ 1 Department of Experimental Clinical Oncology, Aarhus University Hospital, 8200 Aarhus, Denmark; \\ k.g.spindler@rm.dk \\ 2 Department of Oncology, Vejle Hospital, University Hospital of Southern Denmark, 7100 Vejle, Denmark; \\ Lisbeth.Riber@rsyd.dk (L.R.); Birgitte.Mayland.Havelund@rsyd.dk (B.M.H.); Anders.Jakobsen@rsyd.dk (A.J.) \\ 3 Department of Oncology, Herlev and Gentofte Hospital, 2730 Herlev, Denmark; \\ Eva.Serup-Hansen@regionh.dk \\ 4 Danish Centre for Particle Therapy, Aarhus University Hospital, 8200 Aarhus, Denmark; cam.kro@auh.rm.dk \\ 5 Department of Oncology, Aarhus University Hospital, 8200 Aarhus, Denmark; mettfode@rm.dk \\ * Correspondence: karen.lycke.wind@auh.rm.dk \\ + These authors share senior authorship.
}

check for updates

Citation: Wind, K.L.; Riber, L.; Havelund, B.M.; Serup-Hansen, E.; Kronborg, C.; Fode, M.M.; Jakobsen, A.; Spindler, K.-L.G. Intensified Induction Chemotherapy in Locally Advanced Squamous Cell Carcinoma of the Anus-A

Population-Based Experience from the Danish Anal Cancer Group. Cancers 2021, 13, 3226. https:// doi.org/10.3390/cancers13133226

Academic Editors: Christopher L. Hallemeier and Krishan R. Jethwa

Received: 19 May 2021

Accepted: 22 June 2021

Published: 28 June 2021

Publisher's Note: MDPI stays neutral with regard to jurisdictional claims in published maps and institutional affiliations.

Copyright: (c) 2021 by the authors. Licensee MDPI, Basel, Switzerland. This article is an open access article distributed under the terms and conditions of the Creative Commons Attribution (CC BY) license (https:// creativecommons.org/licenses/by/ $4.0 /)$.
Simple Summary: The primary treatment modality for anal cancer is chemoradiotherapy, but patients with locally advanced disease (i.e., large tumors and/or involvement of regional lymph nodes) have a high risk of treatment failure. The use of chemotherapy prior to radiotherapy (induction chemotherapy) can potentially shrink the tumor and/or eradicate small cancer cells with metastatic potential, with a chance of a better outcome. With this paper, the authors present 20 years of nationwide experience with intensified induction chemotherapy in the treatment of locally advanced anal cancer, which indicates a role for further investigation in the most advanced cases.

Abstract: Locally advanced squamous cell carcinoma of the anus (LASCCA) has a poor prognosis with a high risk of treatment failure calling for intensified therapy. We present the long-term followup of a nationwide cohort of LASCCA treated with intensified induction chemotherapy (ICT). The study included patients with LASCCA (T3-4N0 or T1-4N+) treated with at least one cycle of ICT (cisplatin, ifosfamide, leucoverin, and 5-flourouracil) between 1998-2018. Data were retrospectively collected from medical records, and statistics were performed in STATA 16.1. In total, 166 patients with LASCCA were identified. Following ICT, 157 patients (95\%) received primary curative treatment with either radiotherapy $(70 \%)$, chemoradiotherapy $(27 \%)$, or abdominal perineal resection $(3 \%)$. The overall local tumor response rate after ICT was 76\% with 20 (13\%) achieving complete local tumor response. After the primary treatment, 123 patients (79\%) obtained complete response, and 27 underwent salvage surgery due to persistent disease. The median follow-up time was 6 years, local and distant failure rates $22 \%$ and $13 \%$, respectively. The 3- and 5-year disease-free survival rates were $70 \%$ and $67 \%$, and the 3 - and 5 -year overall survival rates were $76 \%$ and $70 \%$, respectively. Intensified ICT regimen could be a supplementary treatment option in the most advanced cases of LASCCA. Prospective randomized trials are needed to investigate this approach further.

Keywords: anus neoplasms; squamous cell carcinoma; induction chemotherapy; radiotherapy; chemoradiotherapy

\section{Introduction}

Squamous cell carcinoma of the anus (SCCA) is a rare malignancy with an incidence between $0.5-1.7$ per 100,000 per year in western countries [1]. The standard treatment is chemoradiotherapy (CRT), which ensures local control for the majority of patients [2]. 
However, locally advanced SCCA (LASCCA) (tumors $\geq 5 \mathrm{~cm}$ and/or regional lymph node metastases) has a poor outcome with high local and distant failure rates [3-6]. Radiotherapy treatment planning in patients with large tumors and multiple lymph node involvement can be complicated by complex target delineation and large target volumes resulting in unacceptable toxicity, and in some advanced cases definitive radiotherapy is not possible. Therefore, these high-risk patients hold a therapeutic challenge, and new treatment strategies to improve the outcome are urgently needed. In this context, induction chemotherapy (ICT) could be a method to downsize before definitive CRT and/or to eradicate micrometastases with the perspective of a better prognosis.

Two randomized trials $[7,8]$ investigating ICT in SCCA have been published, but were not able to show a superior benefit from ICT. However, these trials investigated multiple treatment comparison in all TNM stages and were consequently not statistically designed to determine the effect of ICT in the most advanced stages. A limited number of studies have directly investigated ICT, but with different inclusion criteria, methodological approaches, and small sample sizes. The most commonly used ICT regimen in SCCA has been cisplatin and 5-flourouracil. Encouraging response rates after regimens consisting of ifosfamide and 5-flourouracil in combination with cisplatin and/or leucovorin have been reported in advanced and recurrent cervical cancer [9-12].

With this nationwide population-based study, we present 20 years of experience and long-time follow-up after intensified ICT consisting of cisplatin, ifosfamide, leucovorin, and 5-flourouracil administered prior to definitively intended treatment in patients with LASCCA.

\section{Materials and Methods}

\subsection{Patients}

Patients with T3-T4N0 or T1-4N+ treated with at least one cycle of ICT consisting of cisplatin, ifosfamide, leucovorin, and 5-fluorouracil between 1998 and 2018 were identified through internal registers at the three National Centers treating SCCA: Aarhus University Hospital, Vejle Hospital, and Herlev Hospital. Patient and tumor characteristics, treatment information, treatment response, and outcome data were collected retrospectively from medical records. Collection of data were approved by the Danish Patient Safety Authority (3-3013-2447/1) and the Danish Data Protection Agency (1-16-02-66-18).

The standard diagnostic work-up contained a clinical examination including digital anal examination and endoscopy in combination with either chest $\mathrm{X}$-ray and computer tomography (CT) of the abdomen and pelvis or $\mathrm{CT}$ of the thorax, abdomen, and pelvis. In some cases, the diagnostic work-up also consisted of magnetic resonance imaging (MRI) of the pelvis and transrectal ultrasound, and 18-fluorodeoxyglucose positron emission tomography (FDG PET) CT was introduced as a diagnostic imaging modality during the study period.

Tumor staging is presented by the TNM-classification according to the American Joint Commission on Cancer (AJCC) staging system edition 7 [13] and 8 [14].

\subsection{Treatment}

Induction chemotherapy was administered over 2 days every 4 weeks. The ICT regimen included cisplatin ( $37.5 \mathrm{mg} / \mathrm{m}^{2}$ intravenously (iv.), ifosfamide $\left(2.0 \mathrm{mg} / \mathrm{m}^{2} \mathrm{iv}\right.$.), and 5-flourouracil (500 mg/m $\mathrm{m}^{2}$ iv.) day one and two together with leucovorin $\left(60 \mathrm{mg} / \mathrm{m}^{2}\right.$ iv.) and mesna (500 mg/m $/ \mathrm{m}^{2}$ iv.) administered before ifosfamide and $1 \mathrm{~g} / \mathrm{m}^{2}$ orally at 2 and 6 hours after ifosfamide). Granulocyte colony-stimulating factor (G-CSF) was not standard, but was used at the investigator's discretion and further supportive care as per local practice.

Prescribed curative radiotherapy doses to tumor and pathological lymph nodes were 50-64 Gray (Gy) in 25-32 fractions and 46-54 Gy in 25-32 fractions to the elective nodal areas in five fractions per week. Gross tumor volumes (GTV) were defined based on postICT restaging with clinical and radiographic information. Standard elective nodal areas 
included perirectal, presacral, internal iliac, external iliac, inguinal lymph node areas and the mesorectum depending on the location of the primary tumor and boost to pathological lymph nodes. Clinical target volume margins differed during the 20-year timespan but were generally between $10-20 \mathrm{~mm}$. Treatment was delivered in supine position with 3D conformal technique (1998-2007) or intensity modulated radiation technique (IMRT) (2007-2018). Therapeutic CT was used in all cases with or without MRI and FDG PET-CT in the treatment planning. Concomitant chemotherapy consisted of two cycles of cisplatin and 5-flourouracil, monotherapy with weekly cisplatin, or oral fluoropyrimidine.

\subsection{Response Evaluation, Treatment Failure and Follow-Up}

A clinical response evaluation of the tumor and clinical accessible lymph nodes was performed to assess the efficacy of ICT and to evaluate if curative treatment was possible. Six to eight weeks post radiotherapy a clinical evaluation was performed to assess the efficacy of the primary curative treatment (ICT + definitive radiotherapy/CRT/APR). The standard follow-up program consisted of a clinical examination every 3 to 4 months the first 2 years, then every 6 months for 2 years and after this, every year until 5 years. Imaging during follow-up was used when appropriate.

Complete local tumor response after ICT was defined as the absence of tumor and pathological lymph nodes evaluated by clinical examination. Complete response (CR) after radiotherapy was defined as absence of disease within 6 months after completing radiotherapy evaluated by clinical examination, imaging, and biopsy as appropriate. Persistent disease was defined as residual disease within 6 months after completion of radiotherapy. Treatment failure within the irradiated area after initial complete response was classified as locoregional recurrence. Distant recurrence was defined as metastasis outside the irradiated area after the initial complete response at any point during follow-up.

\subsection{Statistical Methods}

The statistical analyses were performed using STATA 16.1 (STATA/IC16.1, Stata Corp LP, College Station, TX, USA), and survival curves were estimated using the Kaplan-Meier method.

Recurrence was calculated from the date of diagnosis to the date of recurrence (locoregional and/or distant). Locoregional recurrence rate was calculated using the first event of locoregional recurrence. Distant failure rate was calculated using any first distant failure independent of earlier locoregional recurrence.

Overall survival (OS) $(n=166)$ was calculated from the time of diagnosis to death from any cause or date of last observation. Disease-free survival (DFS) on the intended to treat population $(n=166)$ was calculated from the date of diagnosis to progression, recurrence (locoregional or distant), death, or date of last observation-whichever came first. Patients who underwent salvage surgery due to persistent disease were defined as having completed combined curative treatment (ICT + definitive CRT / radiotherapy / APR + salvage surgery in case of persistent disease) and thereby achieved complete response. In the subgroup of patients completing combined curative treatment $(n=151)$, recurrence-free survival (RFS) was calculated from the date of diagnosis to the date of first recurrence (locoregional or distant), death, or date of last observation-whichever came first.

\section{Results}

\subsection{Pre-Treatment Cohort Characteristics}

A total of 166 patients with LASCCA who received at least one cycle of ICT between 1998 and 2018 were identified at the three Hospitals: Aarhus University Hospital $(n=117)$, Vejle Hospital, University Hospital of Southern Denmark $(n=42)$, and Herlev and Gentofte Hospital $(n=7)$. Pre-treatment characteristics are shown in Table 1 . The mean age was 58 (range 29-79) years; the majority of patients were female (79\%) and in good WHO performance status (PS0-1, 82\%). Most tumors were classified as T3 or T4 tumors (82\%) including $38 \%$ infiltrating nearby organs (T4 tumors) and 67\% with regional lymph node metastases. 
Table 1. Pre-treatment characteristics.

\begin{tabular}{|c|c|}
\hline Patient Characteristics & $n=166(\%)$ \\
\hline $\begin{array}{c}\text { Age (year) } \\
\text { Median (range) }\end{array}$ & $58(29-79)$ \\
\hline $\begin{array}{c}\text { Gender } \\
\text { Female } \\
\text { Male }\end{array}$ & $\begin{array}{l}131(79) \\
35(21)\end{array}$ \\
\hline $\begin{array}{c}\text { WHO performance status } \\
0 \\
1 \\
\geq 2 \\
\text { Not available }\end{array}$ & $\begin{array}{c}99(60) \\
3(22) \\
4(2) \\
27(16)\end{array}$ \\
\hline $\begin{array}{c}\text { Tumor size }(\mathrm{cm}) \\
\text { Median (range) }\end{array}$ & $6(1-12)$ \\
\hline $\begin{array}{l}\text { T-stage (AJCC 7th [13] and 8th Edition [14]) } \\
\text { Tx } \\
\text { T1 } \\
\text { T2 } \\
\text { T3 } \\
\text { T4 }\end{array}$ & $\begin{array}{c}- \\
5(3) \\
1(1) \\
24(14) \\
73(44) \\
63(38)\end{array}$ \\
\hline $\begin{array}{c}\text { N-stage (AJCC 8th Edition [14]) } \\
\text { N0 } \\
\text { N1a } \\
\text { N1b } \\
\text { N1c }\end{array}$ & $\begin{array}{c}- \\
55(33) \\
88(53) \\
3(2) \\
20(12)\end{array}$ \\
\hline $\begin{array}{c}\text { N-stage (AJCC 7th Edition [13]) } \\
\text { N0 } \\
\text { N1 } \\
\text { N2 } 2 \\
\text { N3 }\end{array}$ & $\begin{array}{c}- \\
55(33) \\
27(17) \\
42(25) \\
42(25)\end{array}$ \\
\hline $\begin{array}{l}\text { Lymph node location }^{3} \\
\text { Perirectal } \\
\text { Inguinal, unilateral } \\
\text { Inguinal, bilateral } \\
\text { Internal iliac } \\
\text { External iliac }\end{array}$ & $\begin{array}{l}- \\
58(52) \\
49(44) \\
23(21) \\
17(15) \\
24(22)\end{array}$ \\
\hline $\begin{array}{c}\text { Stage (AJCC 8th edition [14]) } \\
\text { Stage IIB } \\
\text { Stage IIIA } \\
\text { Stage IIIB } \\
\text { Stage IIIC }\end{array}$ & $\begin{array}{c}- \\
30(18) \\
26(16) \\
25(16) \\
85(51)\end{array}$ \\
\hline $\begin{array}{c}\text { Stage (AJCC 7th edition [13]) } \\
\text { Stage II } \\
\text { Stage IIIA } \\
\text { Stage IIIB }\end{array}$ & $\begin{array}{l}- \\
30(18) \\
42(25) \\
94(57)\end{array}$ \\
\hline $\begin{array}{l}\text { P16 status } \\
\text { Unknown p16 status } \\
\text { P16 positive } \\
\text { P16 negative }\end{array}$ & $\begin{array}{c}- \\
118(71) \\
44(27) \\
4(2)\end{array}$ \\
\hline
\end{tabular}

${ }^{1}$ Clinical evaluation of largest tumor diameter. In case of missing clinical tumor size, the largest MRI tumor size was used. ${ }^{2}$ Including external iliac lymph node metastasis. ${ }^{3}$ Location of lymph nodes in patients with node positive disease $(n=111)$. Patients may have more than one location, percentage therefore a sum more than 100 . Abbreviations: AJCC, American Joint Committee on Cancer. 


\subsection{Therapy}

Treatment characteristics are summarized in Table 2 . The majority of patients received the intended three cycles $(n=130(78 \%)$, range $1-5)$ of ICT.

Table 2. Treatment characteristics.

\begin{tabular}{cc}
\hline Induction Chemotherapy & $n=\mathbf{1 6 6} \mathbf{( \% )}$ \\
\hline Cycle of ICT & - \\
1 cycle & $11(7)$ \\
2 cycles & $22(13)$ \\
3 cycles & $130(78)$ \\
$>3$ cycles & $3(2)$ \\
\hline Definitive Radiotherapy & $n=\mathbf{1 5 2}(\mathbf{\%})$ \\
\hline Prescribed doses & - \\
$64 / 51.2$ Gy/32F & $115(76)$ \\
$60.2 / 50.4$ Gy/28F & $22(14)$ \\
$60 / 49.5$ Gy/30F & $5(3)$ \\
$60 / 50$ Gy/30F & $3(2)$ \\
Other & $7(5)$ \\
Technique & - \\
IMRT & $108(71)$ \\
3D-conformal radiotherapy & $44(29)$ \\
\hline Concomitant Chemotherapy & $n=42(\%)$ \\
\hline Cisplatin and fluorouracil & $4(10)$ \\
Weekly cisplatin & $21(50)$ \\
Oral fluorouracil & $17(40)$ \\
\hline
\end{tabular}

Abbreviations: ICT, induction chemotherapy; Gy, Gray; IMRT, intensity modulated radiation technique.

A summary of adverse events during ICT is shown in Table 3. In brief, one potential ICT related death was recorded $(0.6 \%)$, and 42 patients $(25 \%)$ were hospitalized due to treatment related toxicity. The most common reason for treatment related hospitalization was neutropenic fever (71\%) followed by nausea, vomiting, and/or dehydration (10\%).

Table 3. Adverse events related to induction chemotherapy.

\begin{tabular}{cc}
\hline Dose Reduction or Discontinuation & $\boldsymbol{n}=\mathbf{1 6 6} \mathbf{( \% )}$ \\
\hline No dose reduction or discontinuation & $99(59)$ \\
Dose reduction or discontinuation of one agent & $46(28)$ \\
Discontinuation of one or more cycles & $18(11)$ \\
Not available & $3(2)$ \\
\hline Hospitalization & $\boldsymbol{n}=\mathbf{1 6 6}(\mathbf{\%})$ \\
\hline No hospitalization during ICT & $103(62)$ \\
Hospitalization during ICT related to ICT & $42(25)$ \\
Hospitalization during ICT NOT related to ICT & $12(7)$ \\
Not available & $9(5)$ \\
\hline Hospitalization with Possible Relation to ICT & $\boldsymbol{n}=\mathbf{4 2}(\mathbf{\%})$ \\
\hline Febrile neutropenia & $30(71)$ \\
Dehydration/nausea/vomiting & $4(10)$ \\
Encephalopathy & $2(5)$ \\
Anemia & $2(5)$ \\
Renal toxicity & $1(2)$ \\
Diarrhea & $1(2)$ \\
Fever without neutropenia & $1(2)$ \\
Unknown cause & $1(2)$
\end{tabular}


A summary of the completed therapy is shown in Figure 1. Definitive radiotherapy was prescribed for 152 cases (CRT $n=42$, radiotherapy only $n=110$ ). No major radiotherapy delays were observed, but in five cases, radiotherapy was omitted and patients underwent abdominal perineal resection (APR) after ICT. In further eight cases, the planned curative treatment was not possible (Figure 1).

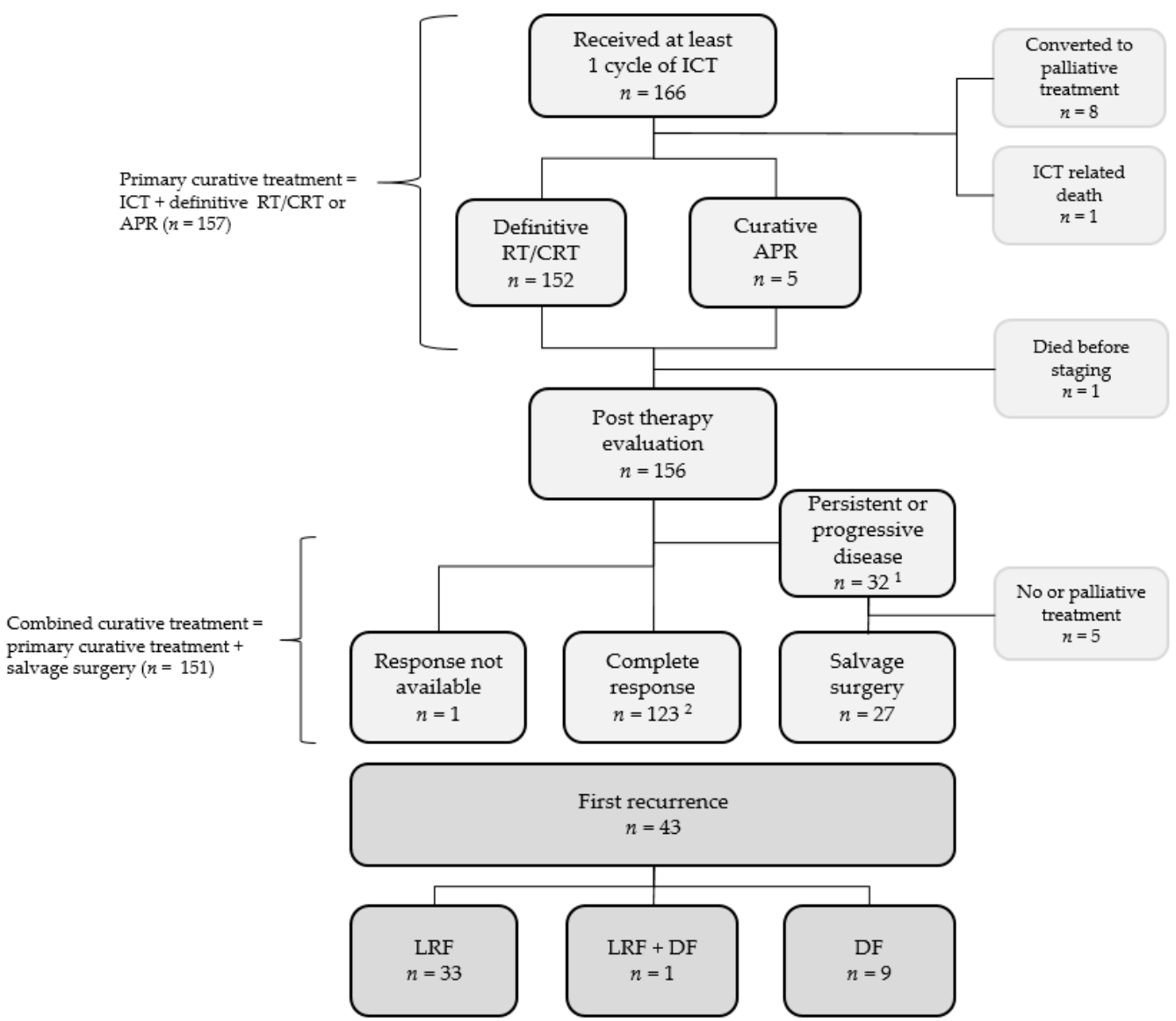

Figure 1. Flowchart of completed therapy, treatment response, and recurrence. ${ }^{1}$ Persistent disease $(n=28)$ and progressive disease $(n=4) .{ }^{2}$ Including three patients with no tumor cells in the specimen after salvage surgery. Abbreviations: RT, radiotherapy; CRT, chemoradiotherapy; APR, abdominal perineal resection; LRF, locoregional failure; $\mathrm{DF}$, distant failure.

\subsection{Treatment Response}

The response rates after ICT are summarized in Table 4. Complete local tumor response was achieved by 20 patients (13\%), and an additional $98(63 \%)$ achieved a partial response (PR). The overall local tumor response rate after ICT alone was $75 \%$.

Within 6 months after primary curative treatment, 123 patients $(79 \%)$ achieved CR, whereas $32(21 \%)$ had persistent disease. Altogether, $91 \%$ successfully completed the combined curative treatment. Not including salvage surgeries for persistent disease, $74 \%$ completed primary curative treatment.

The median follow-up time was 6 years (range $0.3-21.5)$, and 92 patients (55\%) were still alive at the time of the last follow-up. Of the 156 patients who completed the combined curative treatment, 43 patients developed recurrence either locoregional $(n=34)$ and/or distant $(n=20)$ with an overall locoregional recurrence rate of $22 \%$ and a distant failure rate of $13 \%$. Successful salvage surgery was performed in nine cases. Of note, in patients with tumors infiltrating others organs a good local control was observed with a locoregional recurrence rate of $12 \%$. 
Table 4. Response.

\begin{tabular}{cc}
\hline \multicolumn{1}{c}{ Response After ICT $^{\mathbf{1}}$} & $\boldsymbol{n}=\mathbf{1 5 6}(\mathbf{\%})$ \\
\hline Complete local tumor response & $20(13)$ \\
PR & $98(63)$ \\
SD & $26(16)$ \\
PD & $12(8)$ \\
\hline Post Therapy Evaluation ${ }^{1}$ & $\boldsymbol{n}=\mathbf{1 5 5}(\mathbf{\%})$ \\
\hline CR & $123(79)$ \\
Persistent disease & $28(18)$ \\
PD & $4(3)$ \\
\hline${ }^{1}$ Response evaluation after ICT was not available in nine patients and in one patient post therapy, and these were \\
excluded from response rate analysis. Abbreviations: CR, complete response; PR, partial response; SD, stable \\
disease; PD, progression disease.
\end{tabular}

\subsection{Survival Analysis}

Kaplan-Meier survival plots are depicted in Figure 2. Overall survival by stages is presented in Figure 2a. For all stages together, the 3- and 5-year OS was 76\% and 67\%. The 3- and 5-year DFS in the intended to treat population $(n=166)$ was $70 \%$ and $67 \%$, respectively (Figure $2 b$ ). The 3- and 5-year RFS was 76\% and 73\% (Figure $2 \mathrm{c}$ ), in the group of patients who successfully completed the combined curative modality course $(n=151)$.

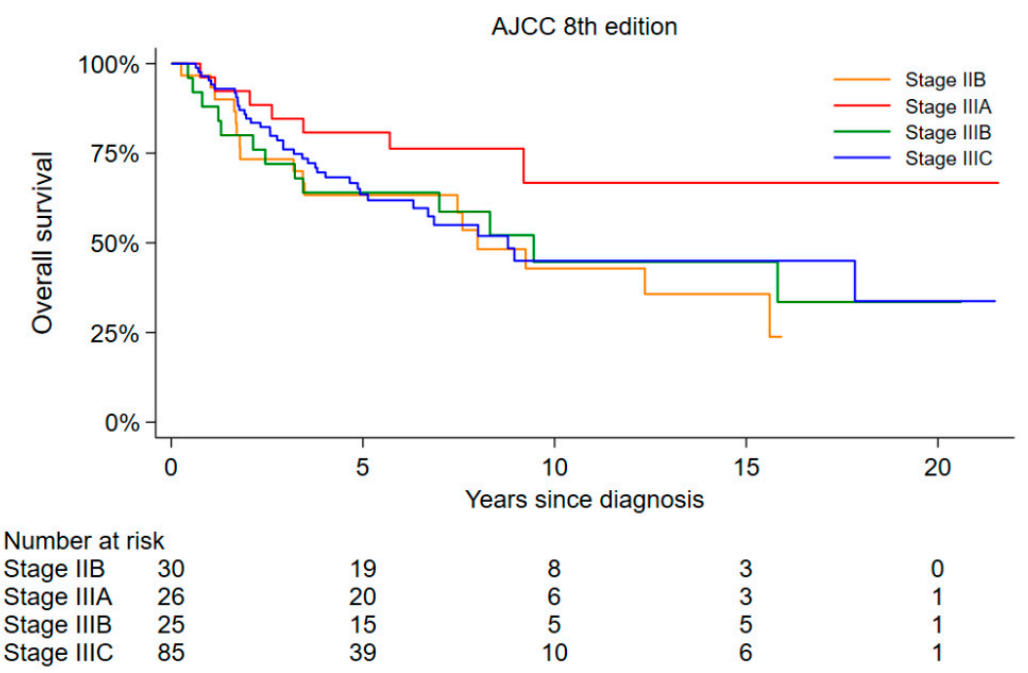

(a)

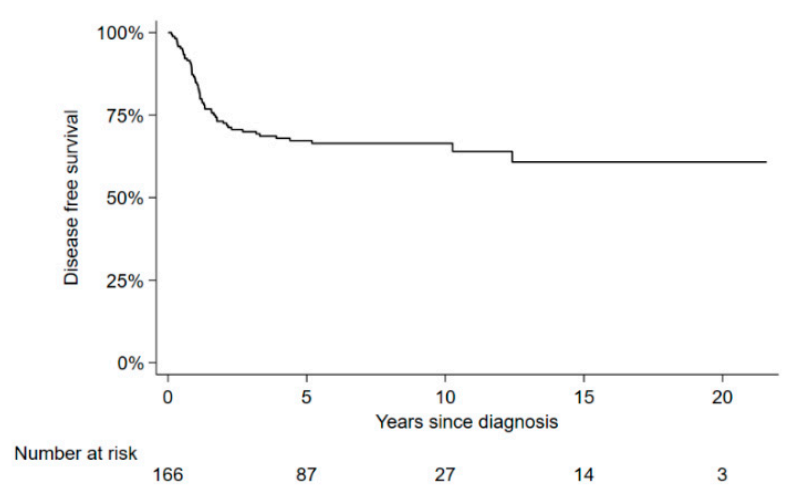

(b)

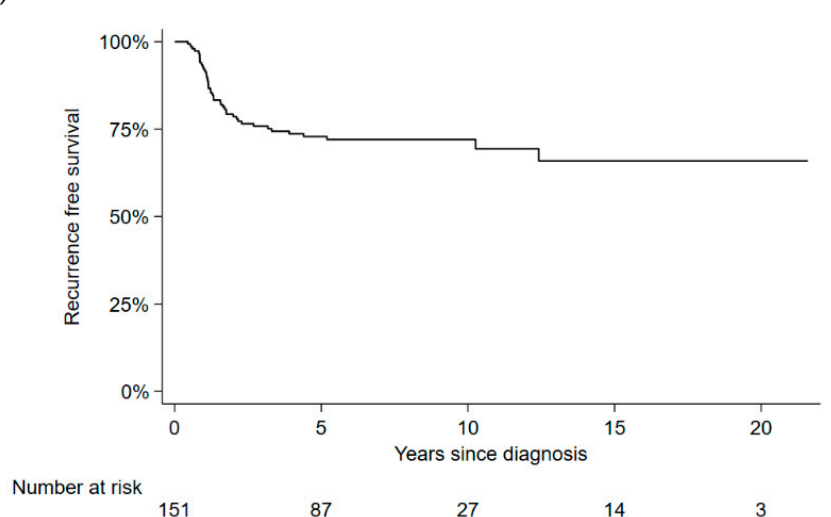

(c)

Figure 2. Kaplan-Maier survival curves. (a) Overall survival by stages ( $n=166)$; (b) disease-free survival $(n=166)$; (c) recurrence-free survival in patients completing combined curative treatment $(n=151)$. 


\section{Discussion}

We present the outcome of a large nationwide cohort of patients within the most advanced group of LASCCA. In the literature, the 3-year DFS in patients with tumors $\geq 5 \mathrm{~cm} \pm$ lymph node positive disease treated with CRT alone is reported between $30 \%$ and $65 \%[3,4,15]$, indicating a need for an intensified treatment strategy for these high-risk patients. The results presented here indicates a considerable effect of ICT in LASCCA with three of four patients having partial or complete response and $91 \%$ completing combined curative treatment. Of these, $74 \%$ achieved $C R$ without salvage surgery.

The current literature on the outcome after ICT in LASCCA is characterized by a small number of heterogeneous studies, and any conclusion from comparison with the present results is difficult and should be drawn with caution. However, ICT has been investigated in two randomized trials-the RTOG-9811 study [7] and the ACCORD 03 trial [8]. These trials did not demonstrate a significant benefit from ICT, but in both studies, the designs included multiple treatment comparison and, more importantly, patients with early-stage disease. In the RTOG-9811 trial, $65 \%$ patients were stage I-II compared to only $18 \%$ in our study. Only $27 \%$ of tumors were larger than $5 \mathrm{~cm}$ compared to $72 \%$ in our cohort. Finally, $67 \%$ of our patients presented with regional lymph node metastases compared to only $30 \%$ in the RTOG-9811 trial. In brief, the RTOG-9811 trial included patients with a good prognosis a priori, and it can be anticipated that the majority of these patients would not benefit from systemic treatment due to early localized and small volume disease. Similarly, in the ACCORD 03 trial only $23 \%$ of patients had N2 or N3 disease compared to $50 \%$ in our study. In addition, $37 \%$ were early stage T1-T2N0-N1 compared to only $3 \%$ in our study. Consequently, these trials are not comparable to our cohort and cannot be concluded to disqualify ICT as an option in the most advanced cases.

A few small studies have reported the use of ICT in LASCCA and a 3-year DFS of approximately $67 \%[16,17]$ in line with the 3 -year DFS in our study. In a population-based study from Sweden [18] a subgroup of 91 patients with LASCCA (tumors more than $4 \mathrm{~cm}$ or lymph node positive) were treated with ICT consisting of cisplatin or carboplatin in combination with 5-flourouracil. Patients who received ICT had a significantly better 5-year OS of $63 \%$, compared to patients with LASCCA not receiving ICT with a 5-year OS of $44 \%$. This supports further investigation of ICT, in the most advanced cases.

In our cohort of the most advanced tumors, treated with an intensified ICT regimen, we observed a promising overall response rate (CR and PR) after ICT of $75 \%$ with $13 \%$ achieving CR and $63 \%$ PR. The ICT did not seem to compromise the full treatment course with only minor treatment delays and a high fraction completing the combined treatment course. No other data have been reported using this triple combination. In retrospective comparison, the overall response rate after ICT with doublet cisplatin and 5-flourouracil varied between $61-71 \%$ and the CR and PR rates between $10-18 \%$ and $51-60 \%$, respectively $[8,16,17]$. In the metastatic setting only moderate response rates have been reported after doublet cisplatin and 5-flourouracil $[19,20]$. Furthermore, CR rates in the metastatic setting with cisplatin, 5-flourouracil, and docetaxel were $42 \%$ in the Epitopes-HPV02 study [21] compared to 5.6\% with doublet cisplatin and 5-flourouracil as reported in a small French study [22]. Conclusively, this supports the investigation of a more intensified regimen.

The possible advantage of intensified therapy should be carefully balanced against the risk of treatment complications and used for selected cases. In the present study, the majority of grade 3-4 treatment related toxicity was neutropenic fever, and we observed one potential ICT related death $(0.6 \%)$. By contrast, while the toxicity profile may vary, the overall frequency of grade 5 events was $2 \%$ in a combined Nordic report on patients treated with various chemotherapy or CRT regimens [23]. We observed a relatively high rate of treatment-related hospitalization of $23 \%$ during ICT. However, with doublet cisplatin and 5-flourouracil alone the rate of grade 3-4 toxicity has been reported between 15 and $33 \%$ [8,17]. While a more intensified treatment strategy for high-risk SCCA is urgently needed, there is an unmet need to define effective treatment options for ICT with feasible 
toxicity profiles. Prospective recording of both toxicity and quality of life data following intensified regimens will be mandatory for further development. Bone marrow support with G-CSF was not routinely used in our cohort. However, we did observe a relatively high rate of neutropenic fever, and it could be argued that the use of G-CSF in relation to this intensified regimen should be standard supportive care. According to the ESMO Clinical Practice Guideline [24], G-CSF is recommended for high risk of neutropenic fever $(>20 \%)$. The use of prophylactic G-CSF would probably lower the rate of neutropenic fever and consequent hospitalization during this intensified treatment.

In this study, we observed a locoregional recurrence rate of $22 \%$ and a distant recurrence rate of $13 \%$ for patients who completed combined curative treatment, and of the 156 patients who completed curative treatment 32 had persistent disease. This cohort is of the most advanced cases, and a high locoregional recurrence rate is expected; however, a distant failure rate of $13 \%$ among these high-risk patients is low. The use of ICT potentially lowers the risk of distant failure by sterilizing micrometastases, and add to downsizing of large tumors thereby decreasing volume and possibly acute and late morbidity. Further intensification of the local treatment (to lower the risk of local failures) should also be considered in future studies, by exploring new radiotherapy techniques and concomitant systemic options like immunotherapy $[25,26]$. Nevertheless, there is an urgent need for tools to improve the selection of patients who will benefit from ICT prior to CRT [27,28].

An aspect to consider is the overall treatment time (OTT). Induction chemotherapy prolongs OTT and this could be of concern to local control as shown in a pooled analysis of RTOG-8704 and -9811 [29], where the authors found that OTT was significantly associated to local failure, but not OS. However, the effect of OTT versus radiation treatment time (RTT) was investigated in locally advanced head and neck squamous cell carcinomas treated with ICT prior to radiotherapy, and here, the authors found that prolonged RTT was significantly associated with locoregional recurrence and OS, whereas prolonged OTT was not associated with these outcomes, when adjusted for RTT [30]. The concern of prolonged RTT is based on the risk of accelerated repopulation, and split course radiotherapy is no longer standard [31,32]. Overall treatment time should also be taken into consideration when treating patients with high risk of distant recurrence, but the direct risk from prolonged OTT due to ICT is not clear.

The data presented here have limitation due to its retrospective nature, but is to our knowledge the largest retrospective dataset on LASCCA treated with ICT, and due to the national registers, we were able to present a data set with very few missing data.

To investigate the use of intensified ICT in the most advanced cases of LASCCA, prospective randomized trials including only the most advanced cases are needed. Future trials should include a control arm of CRT only to compare the effect of ICT in this setting. Here, we describe a cohort treated according to historical practice.

\section{Conclusions}

In conclusion, this is the first study to report on an intensified ICT strategy for LASCCA. Even though ICT is not a recommended standard option, the high response rates, DFS, and OS show proof-of principle of using an intensified ICT regimen in the most advanced cases calling for further clinical investigation.

Author Contributions: Conceptualization, K.-L.G.S. and A.J.; formal analysis, K.L.W.; investigation, K.L.W., L.R., B.M.H., E.S.-H., and M.M.F.; writing-original draft preparation, K.L.W. and K.-L.G.S.; writing-review and editing, K.-L.G.S., A.J., C.K., B.M.H., E.S.-H., L.R., and M.M.F.; funding acquisition, K.-L.G.S. All authors have read and agreed to the published version of the manuscript.

Funding: The research was funded by the Danish Cancer Society, Danish Comprehensive Cancer Center-Radiotherapy, and Aarhus University.

Institutional Review Board Statement: This study was approved by the Danish Patient Safety Authority (3-3013-2447/1) dated 3 September 2018 and the Danish Data Protection Agency (1-16-0266-18) dated 27 February 2018. 
Informed Consent Statement: Patient consent was waived due to the retrospective nature of this study and due to the long-term timespan of this study (1998-2018). Dispensation to informed consent was obtained from the Danish Patient Safety Authority (3-3013-2447/1).

Data Availability Statement: Data not available due to legal restrictions.

Acknowledgments: The work is supported by the Danish Anal Cancer Group.

Conflicts of Interest: The authors declare no conflict of interest. The funders had no role in the design of the study; in the collection, analyses, or interpretation of data; in the writing of the manuscript, or in the decision to publish the results.

\section{References}

1. Islami, F.; Ferlay, J.; Lortet-Tieulent, J.; Bray, F.; Jemal, A. International trends in anal cancer incidence rates. Int. J. Epidemiol. 2017, 46, 924-938. [CrossRef]

2. Shakir, R.; Adams, R.; Cooper, R.; Downing, A.; Geh, I.; Gilbert, D.; Jacobs, C.; Jones, C.; Lorimer, C.; Namelo, W.C.; et al. Patterns and predictors of relapse following radical chemoradiation therapy delivered using intensity modulated radiation therapy with a simultaneous integrated boost in anal squamous cell carcinoma. Int. J. Radiat. Oncol. Biol. Phys. 2020, 106, 329-339. [CrossRef]

3. Ajani, J.A.; Winter, K.A.; Gunderson, L.L.; Pedersen, J.; Benson, A.B.; Thomas, C.R.; Mayer, R.J.; Haddock, M.G.; Rich, T.A.; Willett, C.G. Prognostic factors derived from a prospective database dictate clinical biology of anal cancer: The intergroup trial (RTOG 98-11). Cancer 2010, 116, 4007-4013. [CrossRef]

4. Tomaszewski, J.M.; Link, E.; Leong, T.; Heriot, A.; Vazquez, M.; Chander, S.; Chu, J.; Foo, M.; Lee, M.T.; Lynch, C.A.; et al. Twenty-five-year experience with radical chemoradiation for anal cancer radiation oncology. Int. J. Radiat. Oncol. Biol. Phys. 2012, 83, 552-558. [CrossRef]

5. Das, P.; Bhatia, S.; Eng, C.; Ajani, J.A.; Skibber, J.M.; Rodriguez-Bigas, M.A.; Chang, G.J.; Bhosale, P.; Delclos, M.E.; Krishnan, S.; et al. Predictors and patterns of recurrence after definitive chemoradiation for anal cancer. Int. J. Radiat. Oncol. Biol. Phys. 2007, 68, 794-800. [CrossRef]

6. Glynne-Jones, R.; Sebag-Montefiore, D.; Adams, R.; Gollins, S.; Harrison, M.; Meadows, H.M.; Jitlal, M. Prognostic factors for recurrence and survival in anal cancer. Cancer 2013, 119, 748-755. [CrossRef]

7. Ajani, J.A.; Winter, K.A.; Gunderson, L.L.; Pedersen, J.; Benson, A.B.; Thomas, C.R., Jr.; Mayer, R.J.; Haddock, M.G.; Rich, T.A.; Willett, C. Fluorouracil, mitomycin, and radiotherapy vs. fluorouracil, cisplatin, and radiotherapy for carcinoma of the anal canal-A randomized controlled trial. J. Am. Med. Assoc. 2008, 299, 1914-1921. [CrossRef]

8. Peiffert, D.; Tournier-Rangeard, L.; Gérard, J.P.; Lemanski, C.; François, E.; Giovannini, M.; Cvitkovic, F.; Mirabel, X.; Bouché, O.; Luporsi, E.; et al. Induction chemotherapy and dose intensification of the radiation boost in locally advanced anal canal carcinoma: Final analysis of the randomized UNICANCER ACCORD 03 trial. J. Clin. Oncol. 2012, 30, 1941-1948. [CrossRef]

9. Cadron, I.; Jakobsen, A.; Vergote, I. Report of an early stopped randomized trial comparing cisplatin vs. cisplatin/ifosfamide/5fluorouracil in recurrent cervical cancer. Gynecol. Obstet. Investig. 2005, 59, 126-129. [CrossRef]

10. Etcheverry, M.G.; Marantz, A.; Saine, M.; Litovska, S.; Lewi, D.; Cecchin, G.; Nuñez De Pierro, A. Neoadjuvant chemotherapy with cisplatin, ifosfamide and 5-fluorouracil in the treatment of locally advanced cervical cancer. Int. J. Gynecol. Cancer 2000, 10, 53-58. [CrossRef]

11. Stornes, I.; Mejlholm, I.; Jakobsen, A. A phase II trial of ifosfamide, 5-fluorouracil, and leucovorin in recurrent uterine cervical cancer. Gynecol. Oncol. 1994, 55, 123-125. [CrossRef] [PubMed]

12. Fanning, J.; Ladd, C.; Hilgers, R.D. Cisplatin, 5-fluorouracil, and ifosfamide in the treatment of recurrent or advanced cervical cancer. Gynecol. Oncol. 1995, 56, 235-238. [CrossRef]

13. Edge, S.B.; Byrd, D.R.; Compton, C.C.; Fritz, A.G.; Fritz, A.; Reno, A.; Frederick Greene, N.L.; Trotti, A.; Lee Moffi, H. AJCC Cancer Staging Manual, 7th ed.; Springer: New York, NY, USA, 2010; ISBN 9780387884400.

14. Amin, M.B.; Edge, S.B.; Greene, F.L.; Byrd, D.R.; Brookland, R.K.; Washington, M.K.; Gershenwald, J.E.; Compton, C.C.; Hess, K.R.; Sullivan, D.C.; et al. AJCC Cancer Staging Manual, 8th ed.; Springer: New York, NY, USA, 2017.

15. James, R.D.; Glynne-Jones, R.; Meadows, H.M.; Cunningham, D.; Myint, A.S.; Saunders, M.P.; Maughan, T.; McDonald, A.; Essapen, S.; Leslie, M.; et al. Mitomycin or cisplatin chemoradiation with or without maintenance chemotherapy for treatment of squamous-cell carcinoma of the anus (ACT II): A randomised, phase 3, open-label, $2 \times 2$ factorial trial. Lancet Oncol. 2013, 14, 516-524. [CrossRef]

16. Meropol, N.J.; Niedzwiecki, D.; Shank, B.; Colacchio, T.A.; Ellerton, J.; Valone, F.; Budinger, S.; Day, J.M.; Hopkins, J.; Tepper, J.; et al. Induction therapy for poor-prognosis anal canal carcinoma: A phase II study of the Cancer and Leukemia Group B (CALGB 9281). J. Clin. Oncol. 2008, 26, 3229-3234. [CrossRef]

17. Peiffert, D.; Giovannini, M.; Ducreux, M.; Michel, P.; Francois, E.; Lemanski, C.; Mirabel, X.; Cvitkovic, F.; Luporsi, E.; Conroy, T.; et al. High-dose radiation therapy and neoadjuvant plus concomitant chemotherapy with 5-fluorouracil and cisplatin in patients with locally advanced squamous-cell anal canal cancer: Final results of a phase II study. Ann. Oncol. 2001, 12, 397-404. [CrossRef] 
18. Nilsson, P.J.; Svensson, C.; Goldman, S.; Ljungqvist, O.; Glimelius, B. Epidermoid anal cancer: A review of a population-based series of 308 consecutive patients treated according to prospective protocols. Int. J. Radiat. Oncol. Biol. Phys. 2005, 61, 92-102. [CrossRef]

19. Eng, C.; Chang, G.J.; You, Y.N.; Das, P.; Rodriguez-Bigas, M.; Xing, Y.; Vauthey, J.-N.; Rogers, J.E.; Ohinata, A.; Pathak, P.; et al. The role of systemic chemotherapy and multidisciplinary management in improving the overall survival of patients with metastatic squamous cell carcinoma of the anal canal. Oncotarget 2014, 5, 11133-11142. [CrossRef]

20. Sclafani, F.; Morano, F.; Cunningham, D.; Baratelli, C.; Kalaitzaki, E.; Watkins, D.; Starling, N.; Chau, I.; Rao, S. Platinumfluoropyrimidine and paclitaxel-based chemotherapy in the treatment of advanced anal cancer patients. Oncologist 2017, 22, 402-408. [CrossRef] [PubMed]

21. Kim, S.; François, E.; André, T.; Samalin, E.; Jary, M.; El Hajbi, F.; Baba-Hamed, N.; Pernot, S.; Kaminsky, M.C.; Bouché, O.; et al. Docetaxel, cisplatin, and fluorouracil chemotherapy for metastatic or unresectable locally recurrent anal squamous cell carcinoma (Epitopes-HPV02): A multicentre, single-arm, phase 2 study. Lancet Oncol. 2018, 19, 1094-1106. [CrossRef]

22. Faivre, C.; Rougier, P.; Ducreux, M.; Mitry, E.; Lusinchi, A.; Lasser, P.; Elias, D.; Eschwege, F. 5-fluorouracile and cisplatinum combination chemotherapy for metastatic squamous-cell anal cancer. Bull. Cancer 1999, 86, 861-865. [PubMed]

23. Leon, O.; Guren, M.; Hagberg, O.; Glimelius, B.; Dahl, O.; Havsteen, H.; Naucler, G.; Svensson, C.; Tveit, K.M.; Jakobsen, A.; et al. Anal carcinoma-Survival and recurrence in a large cohort of patients treated according to Nordic guidelines. Radiother. Oncol. 2014, 113, 352-358. [CrossRef] [PubMed]

24. Klastersky, J.; de Naurois, J.; Rolston, K.; Rapoport, B.; Maschmeyer, G.; Aapro, M.; Herrstedt, J.; on behalf of the ESMO Guidelines Committee. Management of febrile neutropaenia: ESMO clinical practice guidelines. Ann. Oncol. 2016, 27, v111-v118. [CrossRef] [PubMed]

25. Morris, V.K.; Salem, M.E.; Nimeiri, H.; Iqbal, S.; Singh, P.; Ciombor, K.; Polite, B.; Deming, D.; Chan, E.; Wade, J.L.; et al. Nivolumab for previously treated unresectable metastatic anal cancer (NCI9673): A multicentre, single-arm, phase 2 study. Lancet Oncol. 2017, 18, 446-453. [CrossRef]

26. Ott, P.A.; Piha-Paul, S.A.; Munster, P.; Pishvaian, M.J.; Van Brummelen, E.M.J.; Cohen, R.B.; Gomez-Roca, C.; Ejadi, S.; Stein, M.; Chan, E.; et al. Safety and antitumor activity of the anti-PD-1 antibody pembrolizumab in patients with recurrent carcinoma of the anal canal. Ann. Oncol. 2017, 28, 1036-1041. [CrossRef]

27. Lefèvre, A.C.; Pallisgaard, N.; Kronborg, C.; Wind, K.L.; Krag, S.R.P.; Spindler, K.-L.G. The Clinical Value of Measuring Circulating HPV DNA during Chemo-Radiotherapy in Squamous Cell Carcinoma of the Anus. Cancers 2021, 13, 2451. [CrossRef]

28. Gilbert, D.C.; Serup-Hansen, E.; Linnemann, D.; Høgdall, E.; Bailey, C.; Summers, J.; Havsteen, H.; Thomas, G.J. Tumourinfiltrating lymphocyte scores effectively stratify outcomes over and above p16 post chemo-radiotherapy in anal cancer. Br. J. Cancer 2016, 114, 134-137. [CrossRef]

29. Ben-Josef, E.; Moughan, J.; Ajani, J.A.; Flam, M.; Gunderson, L.; Pollock, J.D.; Myerson, R.; Anne, R.; Rosenthal, S.A.; Willett, C. Impact of overall treatment time on survival and local control in patients with anal cancer: A pooled data analysis of radiation therapy oncology group trials 87-04 and 98-11. J. Clin. Oncol. 2010, 28, 5061-5066. [CrossRef]

30. Sher, D.J.; Posner, M.R.; Tishler, R.B.; Sarlis, N.J.; Haddad, R.I.; Holupka, E.J.; Devlin, P.M. Relationship between radiation treatment time and overall survival after induction chemotherapy for locally advanced head-and-neck carcinoma: A Subset analysis of TAX 324. Int. J. Radiat. Oncol. Biol. Phys. 2011, 81, e813-e818. [CrossRef]

31. Glynne-Jones, R.; Sebag-Montefiore, D.; Adams, R.; McDonald, A.; Gollins, S.; James, R.; Northover, J.M.A.; Meadows, H.M.; Jitlal, M. 'Mind the gap'-The impact of variations in the duration of the treatment gap and overall treatment time in the first UK anal cancer trial (ACT I). Int. J. Radiat. Oncol. Biol. Phys. 2011, 81, 1488-1494. [CrossRef]

32. Graf, R.; Wust, P.; Hildebrandt, B.; Gögler, H.; Ullrich, R.; Herrmann, R.; Riess, H.; Felix, R. Impact of overall treatment time on local control of anal cancer treated with radiochemotherapy. Oncology 2003, 65, 14-22. [CrossRef] 